\title{
Mercury Exposure in a Riverside Amazon Population, Brazil: A Study of the Ototoxicity of Methylmercury
}

\author{
Ana Hoshino ${ }^{1,2}$ Heloisa Pacheco-Ferreira ${ }^{3}$ Seisse Gabriela G. Sanches ${ }^{4}$ Renata Carvallo ${ }^{5}$ \\ Nathália Cardoso ${ }^{1}$ Maurício Perez ${ }^{1} \quad$ Volney de Magalhães Câmara ${ }^{1}$
}

${ }^{1}$ Universidade Federal do Rio de Janeiro, Instituto de Estudos em Saúde Coletiva, Rio de Janeiro, Brazil

2 Department of Otorhinolaryngology, Faculdade de Medicina da

Address for correspondence Ana Hoshino, PhD, Department of Otorhinolaryngology, Hospital das Clínicas, R. Vigário Albernaz, 843/ Universidade de São Paulo (FMUSP), São Paulo, Brazil

${ }^{3}$ Universidade Federal do Rio de Janeiro, Faculdade de Medicina, Rio de Janeiro, Brazil

4 Universidade de São Paulo, FOFITO, São Paulo, Brazil

${ }^{5}$ FMUSP, FOFITO, São Paulo, São Paulo, Brazil

Int Arch Otorhinolaryngol 2015;19:135-140.

\begin{abstract}
Keywords

- mercury

- methylmercury compounds

- auditory pathways

- medial olivocochlear system

- otoacoustic emissions

- ototoxicity

Introduction Mercury poisoning causes hearing loss in humans and animals. Acute and long-term exposures produce irreversible peripheral and central auditory system damage, and mercury in its various forms of presentation in the environment is ototoxic. Objective We investigated the otoacoustic emissions responses in a riverside population exposed to environmental mercury by analyzing the inhibitory effect of the medial olivocochlear system (MOCS) on transient otoacoustic emissions (TEOAE).

Methods The purpose of the research was to evaluate the entire community independently of variables of sex and age. All of the participants were born and lived in a riverside community. After otolaryngologic evaluation, participants were received tympanometry, evaluation of contralateral acoustic reflexes, pure tone audiometry, and recording of TEOAEs with nonlinear click stimulation. Hair samples were collect to measure mercury levels.

Results There was no significant correlation between the inhibitory effect of the MOCS, age, and the level of mercury in the hair.

Conclusions The pathophysiological effects of chronic exposure may be subtle and nonspecific and can have a long period of latency; therefore, it will be important to monitor the effects of mercury exposure in the central auditory system of the Amazon population over time. Longitudinal studies should be performed to determine whether the inhibitory effect of the MOCS on otoacoustic emissions can be an evaluation method and diagnostic tool in populations exposed to mercury.
\end{abstract}

\section{Introduction}

The health impacts due to acute and/or chronic exposure are already well defined for most chemicals. Organizations such as the US Environmental Protection Agency and World Health Organization established exposure limits, but many people live above this limit. Environmental contamination with persistent pollutants showing toxic and cumulative effects received

November 6, 2014 accepted

December 11, 2014

published online

February 19, 2015
DOI http://dx.doi.org/

10.1055/s-0034-1544115. ISSN 1809-9777.
Copyright $\odot 2015$ by Thieme Publicações License terms Ltda, Rio de Janeiro, Brazil 
on organisms, as in the case of mercury, has reached global proportions due to the persistence and mobility of these substances. ${ }^{1}$ Because it is very toxic and has the tendency to bioaccumulate and because of biomagnification along the food chain, mercury is recognized as a potentially dangerous pollutant in the marine environment.

Historically, two great exposures to methylmercury have occurred. In Minamata (Japan), women showed hair mercury concentrations between 10 and $100 \mu \mathrm{g} / \mathrm{g}$. The other great exposure occurred in Iraq, where women with elevated hair mercury levels $(\sim 10 \mu \mathrm{g} / \mathrm{g})$ had children in whom neurologic alterations were observed after birth. ${ }^{2}$ Passos and Mergler, studying mercury exposure in Amazon communities, reported that even different bioindicators have revealed mean hair mercury levels higher than $15 \mu \mathrm{g} / \mathrm{g}$, which are the highest reported mercury levels in the world. ${ }^{3}$

The Amazon region occupies a prominent place in this scenario, ${ }^{4}$ and the riverside populations of that region suffer the health impacts associated with environmental contamination. Fish, the main source of dietary protein for riverside populations, is consumed at an average of $406 \mathrm{~g} / \mathrm{d}$ and is contaminated with mercury. ${ }^{5}$ The consumption of mercurycontaminated fish gives rise to a series of neurotoxic effects that are observed in pregnant women, fetuses, and newborns, particularly when they are exposed to mercury during brain development. The prenatal exposure may result in small alterations in development that appear over time. ${ }^{6}$

Mercury poisoning causes hearing loss in humans and animals. In a systematic review, the authors conclude that acute and long-term exposures produce irreversible peripheral and central auditory system damage and that mercury in its various forms of presentation in the environment is ototoxic. ${ }^{7}$ The consequences of hearing loss can be irreversible, with clinical alterations that often go undetected by neurologic examination and biological markers, thus jeopardizing the quality of life of these individuals. Follow-up of ototoxicity is important for detecting hearing changes, thereby suggesting new treatment strategies for the patient and intervention when a disabling hearing impairment occurs. ${ }^{8}$

Mercury is a liquid that expands or shrinks very accurately according to the temperature. These particular properties are extremely useful for various applications such as the production of electronic measuring equipment, fluorescent lamps, batteries, dental amalgam, and cosmetics (in small amounts). The mercury used can be released to the environment at different stages of the production, such as industrial gas, industrial waste, and contaminated waste. Thus, it can destroy the soil, air, and water, affecting environmental and human health directly. ${ }^{4}$

Once mercury enters the aquatic ecosystems, the microorganisms transformed into a highly toxic form of mercury called methylmercury, which is accumulated and biomagnifies in fish and shellfish and those who consume them. The levels of methylmercury in some fish species can reach millions of times above the levels present in water from its surroundings.

Even at low doses of exposure, mercury, especially methylmercury, can penetrate the placenta and appear in breast milk. This can disturb development of brain functions and can create deficits in language skills, memory, attention, and motor and visual skills. When exposure to mercury combines with malnutrition, the risk grows considerably.

Mercury exposure can be monitored through hair, blood, breast milk, urine, and nails. The level of mercury in blood and urine shows a recent exposure. Levels in hair reflect longterm exposure. ${ }^{9}$ The Agency for Toxic Substances and Disease Registry estimated that the minimum risk level for methylmercury intake would be $0.3 \mathrm{mg} / \mathrm{kg}$ per day. ${ }^{10}$ This value is based on estimated level of adverse effects (NOAEL) of $1.3 \mathrm{mg} /$ $\mathrm{kg}$ per day calculated for methylmercury hair levels. The estimated level of adverse effects was obtained from a study of the Seychelles population that observed the neurodevelopment of children. ${ }^{9}$

Our objective was to analyze the inhibitory effect of the medial olivocochlear system (MOCS) with transient otoacoustic emissions (TEOAE) responses in a riverside population exposed to environmental mercury. To date,this survey is unprecedented in a population exposed to mercury.

\section{Methods}

\section{Background}

The INPTAm (Instituto Nacional de Pesquisa Translacional da Amazônia) is formed by a group of researchers interested in the health of the environment of the Amazon and its implications for the health of the local population, conducting research in several areas and expecting aggregate knowledge of suitable proposals for improving the quality of life of riverside populations of the Amazon. The INPTAm also works to transfer the knowledge to local professionals, recovery, and environmental protection.

The area selected for the proposed research was the community of Lago do Puruzinho, located in Amazonas state, Brazil. This population was selected for the study because the people are subsistence farmers who are exposed to environmental methylmercury from fish, the primary source of animal protein in their diet.

This study was conducted according to the ethical aspects recommended by Resolution 196/96 of the National Health Council on studies involving humans, and informed consent was obtained from the research subjects. The research was approved by the Ethical Committee (Institutional Review Board/EC) from the Instituto de Estudos em Saúde Coletiva (IESC), under number 79/2011.

All of the participants were born and lived in Puruzinho. None of the participants had a history of any type of auditory problem or otologic surgery. During the study period, the total population of Puruzinho was 102 people. Of these, 83 agreed to participate in the study. Among those who agreed to participate, 25 did not meet the inclusion criteria. The inclusion criteria were as follows: absence of otologic alteration, confirmed by otolaryngologic evaluation and hearing thresholds $\leq 20 \mathrm{~dB}$ hearing level determined by pure tone audiometry $(0.5$ to $8 \mathrm{kHz}$ in octave intervals). Children who did not undergo audiometry were included in the study because they had TEOAEs, type A tympanograms (peak pressure between +20 and -40 daPa; admittance 
between 0.3 and $1.2 \mathrm{~mL}$ ), and presence of contralateral acoustic reflexes. Individuals who showed an absence of TEOAEs or a hearing loss (at any level, of any type, and affecting either ear) were excluded from the study.

The study was conducted among 58 individuals ( 30 females and 28 males) with a mean age of 17.3 years (range 1 to 47 ). The purpose of the research was to evaluate the entire community independently of variables of sex and age. After otolaryngologic evaluation, participants had tympanometry and investigation of contralateral acoustic reflexes (AT-235 Interacoustics, Denmark, Middelfart), pure tone audiometry (AC-33 Interacoustics), and recording of TEOAEs (ILO v6, dual channel, Otodynamics, London, United Kingdom) with nonlinear click stimulation (260 sweeps) presented at $80 \pm 2 \mathrm{~dB}$ peak sound pressure level (SPL). We considered that otoacoustic emissions were present when a signal-to-noise ratio above $3 \mathrm{~dB}$ occurred in at least three frequency bands. The tests, including tonal audiometry, were performed in a very quiet, although not acoustically treated, room. The earphones used in pure tone audiometry were AUDIOCUP (Amplivox Ltd, Oxfordshire, UK) (noise-reducing headset enclosures).

To evaluate the inhibitory effect of the MOCS, a test of linear click-evoked otoacoustic emissions at $60 \pm 2$-dB peak SPL was performed, with and without the contralateral presentation of white noise at $60 \mathrm{~dB}$ SPL (contralateral acoustic stimulation, CAS). White noise was generated by the equipment and delivered in the contralateral ear by a second channel. The presentation mode was alternate, with 10 seconds of TEOAE recording collected without CAS being followed by 10 seconds collected with CAS. The alternating pattern was continued until 260 sweeps in each condition were completed. The final result was the sum of the alternate responses obtained in each condition. The inhibitory effect was calculated from the response values by subtracting the value obtained in the condition with contralateral noise from the value in the condition without contralateral noise (inhibitory effect $=$ TEOAE without CAS - TEOAE with CAS). An inhibitory effect was considered to be present when the result showed a positive value.

The collection of mercury from hair samples was conducted by professionals from the Universidade Federal de Rondônia. Hair samples underwent digestion and chemical oxidation with nitric acid $\left(\mathrm{HNO}_{3}\right)$ and potassium permanganate $\left(\mathrm{KMnO}_{4}\right)$. A total mercury assay was conducted at the Universidade Federal de Rondônia, utilizing an atomic absorption spectrophotometry technique through generation of cold vapor (Flow Injection Mercury System, FIMS400 by Perkin Elmer, Waltham, Massachusetts). The mercury assay was performed on 38 individuals who consented to participate in the study. The mean mercury level in the hair samples was $11.26 \mu \mathrm{g} / \mathrm{g}$ (range 2.93 to 23.45). Participants were classified into three groups according to detected levels of mercury: group 1, up to $6 \mu \mathrm{g} / \mathrm{g}$; group 2 , from 6.1 to $14.9 \mu \mathrm{g} / \mathrm{g}$; and group $3, \geq 15 \mu \mathrm{g} / \mathrm{g}$.

For the statistical analysis, the measures of central tendency and dispersion were calculated for all the numerical variables, and the measures of frequency and percentage frequency were calculated for all the categorical and ordinal

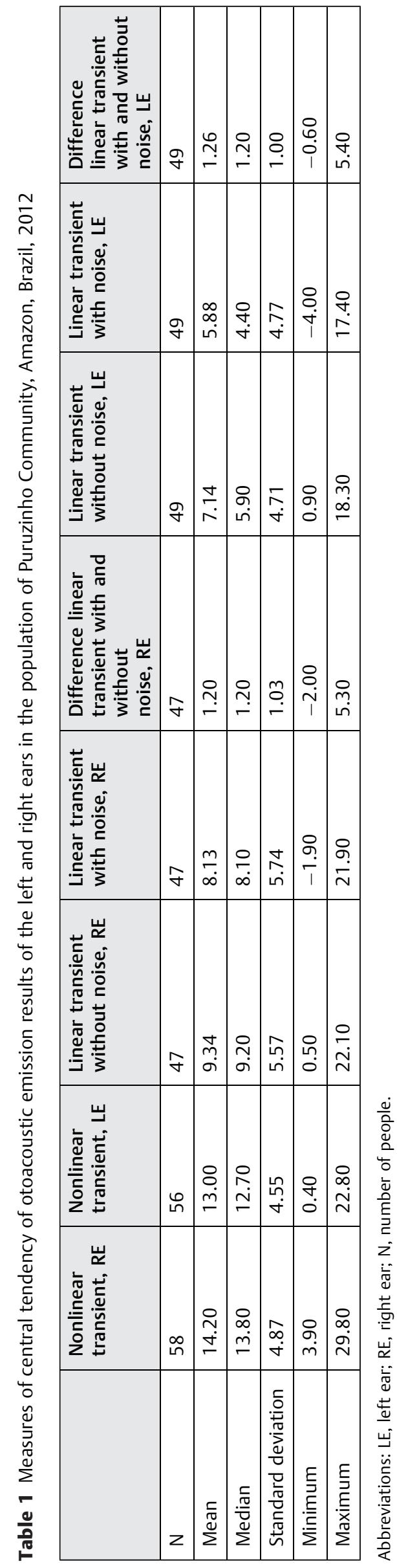


Transient linear difference with and without noise, right ear

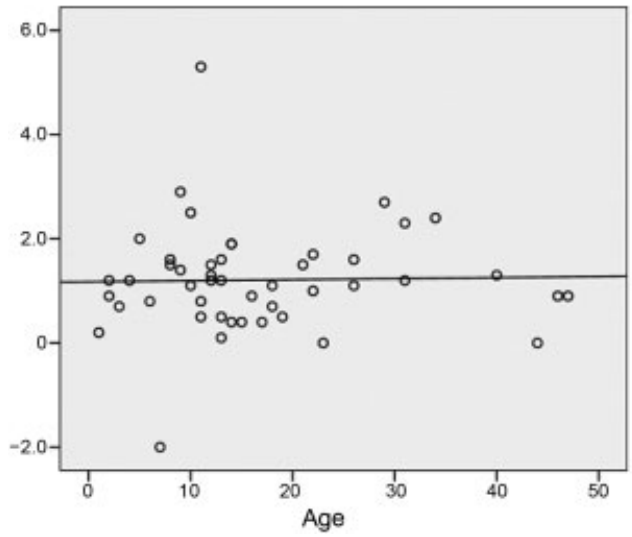

Transient linear difference with and without noise, left ear

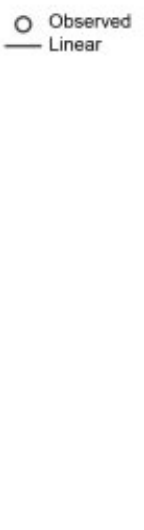

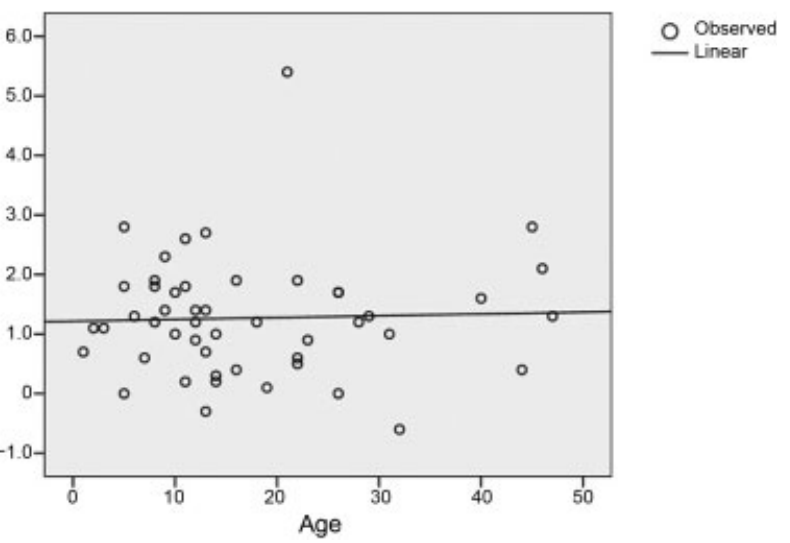

Fig. 1 Inhibition of medial olivocochlear system values of the right ear and left ear compared with ages of the population from Puruzinho Community, Amazon, Brazil, 2012.

variables. The comparison between the discrete variables noted in tables was calculated by the chi-square test with Yates' correction. In the correlation analysis, the Pearson test was used to measure the linear association between two variables. The comparison of means was performed by unpaired Student $t$ test. The data were analyzed using the Statistical Package for the Social Sciences program (SPSS version 14.0, IBM, NY, USA). The level of significance was set at $p<0.05$.

\section{Results}

The presence of nonlinear TEOAEs was observed in all research participants for the right ear and in 56 participants for the left ear (-Table 1). It is important to emphasize that, in the absence of response, the affected side was excluded for evaluation of TEOAEs with linear click stimuli. Among 58 right ears, 47 showed linear TEOAEs for stimulations of $60 \mathrm{~dB}$ SPL (sound pressure level) with and without contralateral noise, and these were considered for analysis. Among 56 left ears, 49 showed linear TEOAEs and were considered for analysis. The mean linear TEOAEs were $9.34 \mathrm{~dB}$ for the right ear and $7.14 \mathrm{~dB}$ for the left ear. The mean value of the inhibitory effect of the MOCS was $1.20 \mathrm{~dB}$ for the right ear and $1.26 \mathrm{~dB}$ for the left ear.

There was no significant correlation between the values of the inhibitory effect for the right and left ears and age ( - Fig. 1 ). Furthermore, there was no significant correlation between values of the inhibitory effect and hair mercury levels (-Fig. 2).

Among the 58 participants, 7 (12\%) showed an absence of inhibitory effect of the MOCS. The mean level of mercury in the hair of these individuals was $12.78 \mu \mathrm{g} / \mathrm{g}$. Five participants had hair mercury levels above the acceptable limit according to the World Health Organization $(6.0 \mu \mathrm{g} / \mathrm{g})$. Two participants were not tested (-Table $\mathbf{2}$ ).

- Table 3 shows participants classified into three groups according to their hair mercury levels. Individuals who showed altered results of the inhibitory effect of the MOCS in both right and left ears were excluded from each group (groups 1,2, and 3). The mean amplitude of the inhibitory
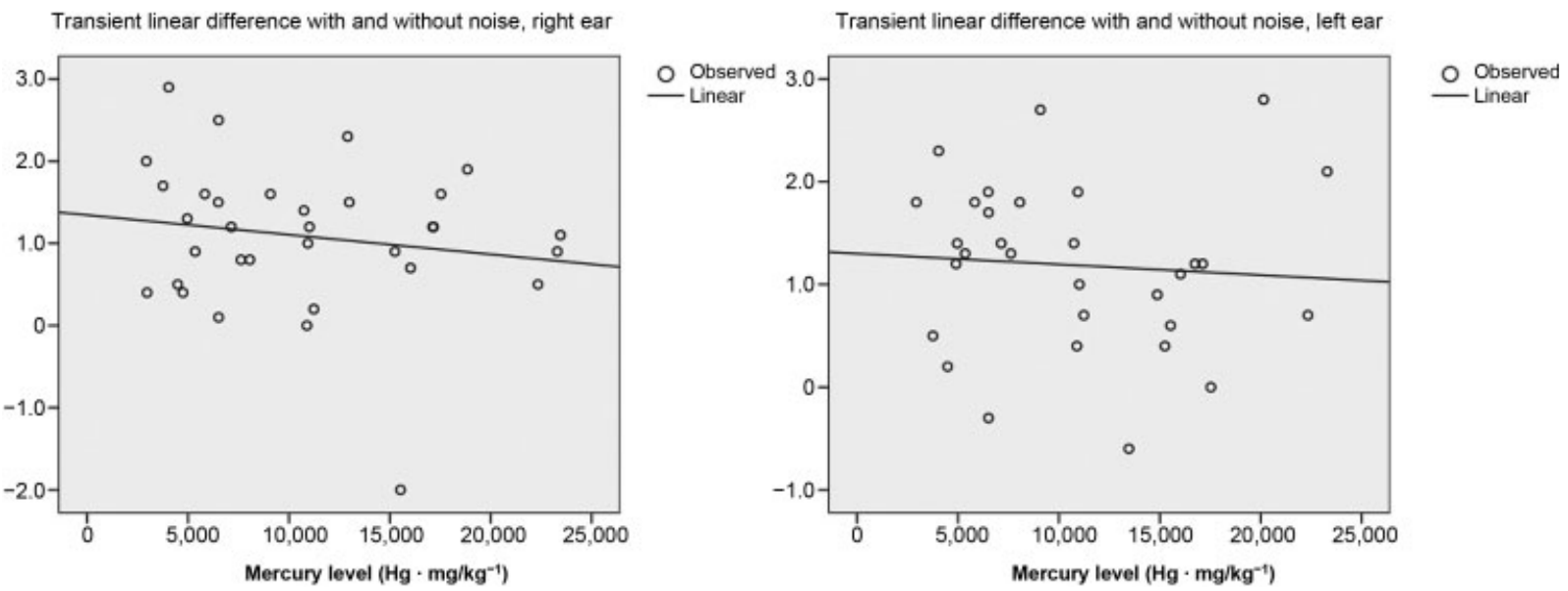

Fig. 2 Inhibition of medial olivocochlear system values of the right ear and left ear compared with hair mercury levels in the population of Puruzinho Community, Amazon, Brazil, 2012. 
Table 2 Amplitude values of linear TEOAE, inhibitory effect, and mercury levels for participants with altered examinations from the population of Puruzinho Community, Amazon, Brazil, 2012

\begin{tabular}{|l|l|l|l|l|l|l|l|}
\hline Patient no. & $\begin{array}{l}\text { Linear TEOAE } \\
\text { without noise } \\
(\mathrm{dB}), \mathrm{RE}\end{array}$ & $\begin{array}{l}\text { Linear TEOAE } \\
\text { with noise } \\
(\mathrm{dB}), \mathrm{RE}\end{array}$ & $\begin{array}{l}\text { Difference } \\
(\mathrm{dB})\end{array}$ & $\begin{array}{l}\text { Linear TEOAE } \\
\text { without noise } \\
(\mathrm{dB}), \text { LE }\end{array}$ & $\begin{array}{l}\text { Linear TEOAE } \\
\text { with noise } \\
(\mathrm{dB}), \text { LE }\end{array}$ & $\begin{array}{l}\text { Difference } \\
(\mathrm{dB})\end{array}$ & $\begin{array}{l}\text { Mercury } \\
\text { levels }(\boldsymbol{\mu g} / \mathrm{g})\end{array}$ \\
\hline 1 & Excluded & Excluded & Excluded & 3.80 & 3.80 & 0.0 & ND \\
\hline 2 & 3.80 & 3.80 & 0.0 & 0.90 & 0.00 & 0.9 & ND \\
\hline 3 & 8.20 & 8.10 & 0.1 & 3.10 & 3.40 & -0.3 & 6.51 \\
\hline 4 & 5.20 & 5.20 & 0.0 & 2.60 & 2.20 & 0.4 & 10.89 \\
\hline 5 & Excluded & Excluded & Excluded & 3.30 & 3.90 & -0.6 & 13.46 \\
\hline 6 & 5.30 & 7.30 & -2.00 & 2.10 & 1.50 & 0.6 & 15.53 \\
\hline 7 & 11.40 & 9.80 & 1.60 & 7.40 & 7.40 & 0.0 & 17.53 \\
\hline
\end{tabular}

Abbreviations: LE, left ear; ND, not determined; RE, right ear; TEOAE, transient otoacoustic emissions.

Table 3 Suppression mean distribution in individuals participating in the hair mercury level research across three groups

\begin{tabular}{|c|c|c|c|}
\hline Average & G1 $0-6 \mu g / g ~ H g ~(n=10)$ & G2 6.1-14.9 $\mu \mathrm{g} / \mathrm{g} \mathrm{Hg}(n=13)$ & $\mathrm{G} 3 \geq 15 \mu \mathrm{g} / \mathrm{g} \mathrm{Hg}(n=10)$ \\
\hline $\mathrm{Hg}$ & 4.39 & 9.97 & 19.03 \\
\hline Suppression of RE & 1.17 & 1.22 & 0.84 \\
\hline Suppression of LE & 1.05 & 1.28 & 0.95 \\
\hline
\end{tabular}

Abbreviations: LE, left ear; RE, right ear.

Note: G1 had exposure within allowable limit according to the World Health Organization, G2 had exposure between 6.10 to $14.90 \mu \mathrm{g} / \mathrm{g}$, and G3 had exposure $\geq 15 \mu \mathrm{g} / \mathrm{g}$.

effect of the MOCS was lower for participants with higher concentrations of mercury in their hair.

\section{Discussion}

The same team that analyzed the mercury levels for this project also analyzed hair mercury levels of the Puruzinho population in 2005 to 2006 . $^{5}$ The median values in the female and male populations were $12.93 \mu \mathrm{g} / \mathrm{g}$ (range 2.48 to 57.04 ) and $18.41 \mu \mathrm{g} / \mathrm{g}$ (range 2.28 to 70.56 ), respectively. In the present study, the median value was $10.91 \mu \mathrm{g} / \mathrm{g}$ (range 2.93 to 23.45). The population remains exposed to high levels of methylmercury that are comparable to the historical great exposures of populations in other parts of the world.

Several studies concerning the inhibitory effect of the efferent pathway demonstrated an asymmetry between the right and left ears, suggesting an advantage of effectiveness of the right ear and dominance of the left hemisphere. ${ }^{11}$ The inhibitory effect of the MOCS and the measure of the TEOAE amplitude in children and adults are valid indicators of peripheral auditory lateralization; however, they are independent. ${ }^{12}$ Such asymmetry may be related to the effectiveness of the efferent system in processing acoustic signals and, consequently, to its role in auditory performance with background noise. The Puruzinho population showed higher amplitude of responses evaluated by the TEOAEs for the right ear; however, the inhibitory effect of the efferent pathway was equivalent for both sides, and an advantage of the right ear was not seen, contrary to other studies.

We observed that the amplitude of responses of the right and left ears showed a tendency to decrease as the mercury levels increased significantly. A previous study reported that higher biological marker values are associated with increased presence of signals and symptoms of exposure. ${ }^{13}$

The inhibitory effect values of the MOCS in the Puruzinho population did not present a significant correlation with age. This may be because the Puruzinho population is a young population, with a mean age of 17.3 years and a maximum age of 47 years.

It was not possible to correlate mercury levels with the inhibition of otoacoustic emissions; similarly, it was not possible to conclude that the $12 \%$ ( 7 participants) of the population who showed absence of the inhibitory effect of the MOCS had alterations arising from exposure to methylmercury. Population studies concerning the inhibition of otoacoustic emissions cannot be found in the literature.

The population presented high levels of long-term exposure to methylmercury. The lack of a significant relationship between the results of the auditory evaluation and hair mercury levels at the time the hair samples were collected should not be interpreted as implying that mercury does not alter the efferent auditory system. For this analysis, a longitudinal monitoring of the population and a higher number of individuals participating in the research would be necessary.

The pathophysiological effects of chronic exposure may be subtle and nonspecific and have a long period of latency ${ }^{14}$; therefore, it will be important to monitor the effects of mercury exposure in the central auditory system of the Puruzinho population over time.

Limitations can be pointed out for this study: the number of residents that agreed to participate in the study; the young 
population that prevented comparisons between age groups; and the difficulty in finding a control group that was not exposed to mercury in a riverside population.

\section{Conclusions}

The Amazon population, and in particular the riverside population in which fish is a main source of dietary protein, should be clinically monitored. Some studies, taking into account utilization of different methodologies, point toward the possibility that the Amazon region is seeing the significant silent action of methylmercury in exposed riverside populations, ${ }^{14}$ with the presumable appearance of the clinical expression of mercury poisoning in the Amazon.

Although the literature refers to mercury as ototoxic, damaging the afferent auditory system, this study cannot claim that methylmercury alters the function of the MOCS. Existing studies indicate that the inhibitory effect of the MOCS is a promising tool for evaluation of the efferent auditory pathways, and its specificity is very important for diagnosing central auditory disorders.

The present study proposes that longitudinal monitoring studies of the riverside population should be performed to learn whether analysis of the inhibitory effect of the MOCS by measuring otoacoustic emissions may be used as an evaluation method and diagnostic tool in populations exposed to mercury.

It is important to emphasize that this study is an initial and exploratory study; therefore, the results may be used as a reference for new studies of other populations exposed to methylmercury and may help to open new frontiers for multidisciplinary research.

\section{Declaration of Interest}

The authors report no conflicts of interest.

\section{Funding}

This work was supported by the INCT for Translational Research in Health and Environment in the Amazon Region (Public notice MCT/CNPq $n^{\circ}$ 015/08-National Institutes of Science and Technology).

\footnotetext{
Acknowledgments

I would like to thank Dra. Denise Carvalho (INPETAM) and Dra. Jaqueline Quintanilha Brucha (UFRJ) for the scientific contributions.
}

\section{References}

1 Dias ACL, Guimarães JR, Malm O, Costa PA. Mercúrio total em músculo de cação Prionace glauca (Linnaeus, 1758) e de espadarte Xiphias gladius Linnaeus, 1758, na costa sul-sudeste do Brasil e suas implicações para a saúde pública. Cad Saude Publica 2008; 24(9):2063-2070

2 Castoldi AF, Johansson C, Onishchenko N, et al. Human developmental neurotoxicity of methylmercury: impact of variables and risk modifiers. Regul Toxicol Pharmacol 2008;51(2): 201-214

3 Passos CJS, Mergler D. Human mercury exposure and adverse health effects in the Amazon: a review. Cad Saude Publica 2008; 24(4, Suppl 4):s503-s520

4 OPAS/OMS. Cooperación técnica entre Brasil, Bolivia e Colômbia: teoría y prática para el fortalecimiento de la vigilancia de salud de poblaciones expuestas a mercúrio. 2011. Available at: http:// www.paho.org/bra/index.php?option=com_docman\&task=doc download\&gid=1428\&Itemid $=423$. Accessed October 21, 2013

5 Oliveira RC, Dórea JG, Bernardi JVE, Bastos WR, Almeida R, Manzatto AG. Fish consumption by traditional subsistence villagers of the Rio Madeira (Amazon): impact on hair mercury. Ann Hum Biol 2010;37(5):629-642

6 Giordano G, Costa LG. Developmental neurotoxicity: some old and new issues. ISRN Toxicol 2012:2012:814795

7 Hoshino ACH, Ferreira HP, Malm O, Carvallo RM, Câmara VM. A systematic review of mercury ototoxicity. Cad Saude Publica 2012; 28(7):1239-1248

8 American Academy of Audiology (AAA)-Position Statement and Clinical Practice Guidelines. Ototoxicity monitoring. October 2009. Available at: http://www.audiology.org/publicationsresources/document-library/ototoxicity-monitoring Acessed in January 2014

9 ATSDR-Agency for Toxic Substances and Disease Registry. Toxicological profile for mercury. Atlanta, GA: U.S. Department of Health and Human Services, Public Health Service; 1999

10 ATSDR-Agency for Toxic Substances and Disease Registry. Technical support document for a methylmercury reference dose as a basis for fish consumption screening values (FCSVs). [cited 2013 Jan 31]. Available at: http://www.atsdr.cdc.gov/hac/pha/MethylmercuryReference/TechnicalSupportDocumentforAMethylcercuryReferenceDoseasaBasisforFCSVs9-10-2009.pdf. Accessed in January 17, 2012

11 Khalfa S, Collet L. Functional asymmetry of medial olivocochlear system in humans. Towards a peripheral auditory lateralization. Neuroreport 1996;7(5):993-996

12 Durante AS, Carvallo RMM, da Costa FS, Soares JC. [Characteristics of transient evoked otoacoustic emissions in newborn hearing screening program]. Pro Fono 2005;17(2):133-140

13 Choi AL, Weihe P, Budtz-Jorgensen E, et al. Methylmercury exposure and adverse cardiovascular effects in Faroese whaling men environmental. Environmental Health Perspectives 2009;117(3): 367-372

14 Pacheco-Ferreira H. [Estudo dos efeitos a saúde em populações ribeirinhas expostas ao mercúrio na Amazônia] [PhD Thesis]. Belém, Brazil: Universidade Federal do Pará; 2001 